\title{
Пищевой продукт специализированного назначения для коррекции нарушений углеводного обмена
}

\author{
М.И. Калимуллин ${ }^{1}$, С.-С.С. Сади ${ }^{1}$, А.Н. Австриевских ${ }^{2}$, В.М. Позняковский ${ }^{3 *}$ \\ ${ }^{1}$ Кузбасская государственная сельскохозяйственная академия, г. Кемерово, Российская Федерация \\ ${ }^{2}$ НПО «Арт Лайф», г. Томск, Российская Федерация \\ зуральский государственный экономический университет, г. Екатеринбург, Российская Федерация, *e-mail: pvm1947@bk.ru
}

\section{Ключевые слова:} специализированный продукт;

регламентированные показатели качества; безопасность; функциональные свойства; эффективность; промышленная апробачия

\begin{abstract}
Реферат
Разработаны рецептура и технология производства специализированного продукта в форме биологически активной добавки (БАД) для коррекции нарушений обмена веществ при сахарном диабете (СД). Установлены регламентируемые показатели пищевой ценности - в одной таблетке, мг, не менее: витамин С - 8,6; хром - 0,01; цинк - 2,3; флавоноиды - 10; танины - 20; марганец - 0,8. Результаты микробиологических и токсикологических испытаний свидетельствуют о санитарно-гигиеническом благополучии БАД по истечении 39 месяцев хранения, что позволило установить срок реализации - 3 года с «запасом прочности» 3 месяца при комнатной температуре в сухом защищенном от света месте. Функциональная направленность разработанного продукта подтверждена результатами клинических исследований путем включения в рацион больных сахарным диабетом. Испытуемые основной группы - 44 пациента - получали диетическое питание (9-й стол), БАД по 2 таблетки 2 раза в день в комплексе с противодиабетическим препаратом «Манинил-5» в дозе 2 таблетки 2 раза в день во время еды на протяжении месяца. Группу контроля составляли 44 больных, получавших аналогичный рацион и противодиабетическую терапию без

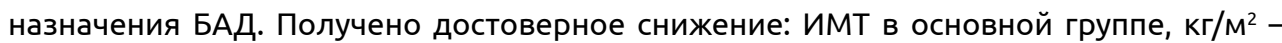
с 35,1 $\pm 1,5$ до 30,3 $\pm 1,5$; систолического и диастолического АД, мм рт. ст. соответственно в основной и контрольной группе больных $-135 \pm 2,6-121 \pm 2,8$ и 83,7 $\pm 1,4-75 \pm 1,6$. Аналогичные изменения отмечены по показателю содержания глюкозы в венозной

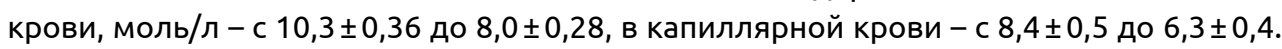
Установлена достоверная динамика снижения базальной и пищевой гликемии через

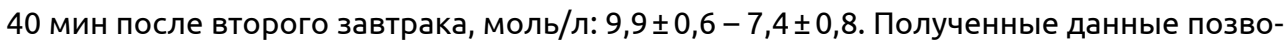
лили рекомендовать БАД для профилактики и комплексного лечения сахарного диабета. Специализированный продукт апробирован на предприятиях НПО «Арт Лайф» (г. Томск, Россия).
\end{abstract}

\section{Specialized Food Product for Carbohydrate Metabolism Disorders Correction}

\author{
Marat I. Kalimullin', Sai-Suu S. Sadi', Aleksandr N. Avstriyevskikh², \\ Valeriy M. Poznyakovskiy * \\ ${ }^{1}$ Kuzbass State Agricultural Academy, Kemerovo, Russian Federation \\ 2Scientific and Production Association "Art Life", Tomsk, Russian Federation \\ 3ural State University of Economics, Ekaterinburg, Russian Federation, *e-mail: pvm1947@bk.ru
}


Keywords:

specialized product; regulated indicators of quality;

security;

functional property;

efficiency;

industrial testing

\section{Abstract}

The article concerns the formulation and production technology development of a specialized product in the form of a biologically active additives (BAA) for the correction of metabolic disorders in the diabetes mellitus (DM). The authors determined regulated indicators of food value in one pill, not less than: vitamin C $-8.6 \mathrm{mg}$; chrome $-0.01 \mathrm{mg}$; zinc $-2.3 \mathrm{mg}$; flavonoids - $10 \mathrm{mg}$; tannins - $20 \mathrm{mg}$; manganese $-0.8 \mathrm{mg}$. The results of microbiological and toxicological tests indicate the sanitary and hygienic safety of biologically active additives after 39 months of storage, which allowed to establish the implementation period of 3 years with an "assurance coefficient" of 3 months at room temperature in a dry place protected from light. The researches confirmed the functional focus of the developed product by the results of clinical studies by inclusion in the diet of patients with diabetes mellitus. The main research group consists of 44 patients. They received dietary food (table 9), 2 pills of the BAA 2 times a day combined with 2 pills of the antidiabetic drug "Maninil-5" 2 times a day during meals for a month. The control group involved 44 patients receiving a similar diet and antidiabetic therapy without BAA. There was a significant decrease in BMI in the main group from $35.1 \pm 1.5$ to $30.3 \pm 1.5 \mathrm{~kg} / \mathrm{m} 2$; systolic and diastolic blood pressure was from $135 \pm 2.6$ to $121 \pm 2.8 \mathrm{~mm} \mathrm{Hg}$ in the main group and from $83.7 \pm$ \pm 1.4 to $75 \pm 1,6 \mathrm{~mm} \mathrm{Hg}$ in the control group. Similar changes were in the case of glucose in venous blood - from $10.3 \pm 0.36$ to $8.0 \pm 0.28 \mathrm{~mol} / \mathrm{L}$, in capillary blood-from $8.4 \pm 0.5$ to $6.3 \pm$ $\pm 0.4 \mathrm{~mol} / \mathrm{L}$. There is a significant decrease in basal and food glycemia in 40 minutes after lunch: $9,9 \pm 0,6-7,4 \pm 0,8 \mathrm{~mol} / \mathrm{L}$. The obtained data allowed to recommend BAA for the prevention and complex treatment of diabetes. The specialized product is approved at the enterprises of Scientific and Production Association “Art Life” (Tomsk, Russia).

For citation: Marat I. Kalimullin, Sai-Suu S. Sadi, Aleksandr N. Avstriyevskikh, Valeriy M. Poznyakovskiy. Specialized Food Product for Carbohydrate Metabolism Disorders Correction. Индустрия numaния|Food Industry. 2019. Vol. 4, No. 3. Pp. 58-64. DOI 10.29141/25001922-2019-4-3-7

\section{Актуальность}

Производство специализированных продуктов - одно из приоритетных направлений развития пищевой и перерабатывающей промышленности России ${ }^{1}$. На современном этапе особое внимание уделяется разработке биологически активных добавок (БАД) с направленными функциональными свойствами, оценке их качества, безопасности и эффективности.

Накопленный отечественный и зарубежный опыт убедительно свидетельствует, что использование БАД - наиболее доступный, экономически целесообразный и эффективный путь коррекции обменных процессов, характеризующих здоровье и питание современного человека [1; $2 ; 3 ; 4]$. Важное значение этот вектор нутрициологии приобретает в профилактике и комплексном лечении сахарного диабета (СД) $[5 ; 6 ; 7 ; 8]$.

Цель работы - определить регламентируемые показатели качества и функциональные свойства специализированного продукта для коррекции обменных процессов при сахарном диабете.

\footnotetext{
${ }^{1}$ Стратегия развития пищевой и перерабатывающей промышленностиРоссийскойФедерациинапериоддо2020г.:распоряжение Правительства Российской Федерации от 17 апреля 2012 г. № 559-р.
}

\section{Материалы и методы исследования}

Исследования проводились на базе аккредитованных испытательных лабораторий Кемеровского государственного сельскохозяйственного института, Научно-производственного объединения «Арт Лайф» (г. Томск), ФГБУН «ФИЦ питания и биотехнологии» (г. Москва), Областной клинической больницы г. Томска. В ходе исследования использованы исходные сырьевые ингредиенты, полуфабрикаты и готовая продукция в форме БАД.

Проведены органолептические, физико-химические и микробиологические исследования специализированного продукта в процессе производства и хранения при комнатной температуре в сухом защищенном от света месте в течение 39 месяцев. Показатели качества и безопасности определялись согласно требованиям технического регламента².

Клинические испытания выполнены на репрезентативной группе больных сахарным диабетом II типа - 88 человек (мужчины и женщины)

\footnotetext{
2 О безопасности отдельных видов специализированной пищевой продукции, в том числе диетического, лечебного и диетического профилактического питания: Технический регламент ТС 027/2012 / утв. решением Совета Евразийской экономический комиссии от 5 июня 2012 г. № 34.26 с.
} 
в возрасте 47-67 лет. Основную группу составили 44 пациента, которым было назначено диетическое питание (9-й стол) по 2 таблетки 2 раза в день БАД во время еды в комплексе с противодиабетическим препаратом «Манинил-5» в аналогичном количестве. В группу контроля входили 44 испытуемых, получавших такую же диетотерапию в комплексе с фармпрепаратом, без назначения БАД.

Применялись общедоступные и специальные методы исследования показателей безопасности и качества используемого сырья и готовых форм БАД, а также их эффективности и функциональной направленности. Сумму изомеров ГХЦГ, ДДТ, содержание гептахлора и алдрина исследовали с помощью газо-жидкостной хроматографии (хроматограф Agilent 6890 N) (ГОСТ 30349); токсичные металлы (ГОСТ 30178) - ртуть, мышьяк, свинец, кадмий, минералы - цинк (Р 4.1.1672), марганец и хром (ГОСТ 30178) - с применением атомно-абсорбционной спектрофотометрии (спектрофотометр Varian 220 A). Сумму флавоноидов определяли УФ-спектрофотометрическим методом (с использованием хроматографа Agilent) в пересчете на рутин (ГФ ХІ. Вып. 2. Ст. 56).

\section{Результаты исследования и их обсуждение}

Разработан биоактивный комплекс в таблетированной форме БАД, представляющий собой растительную композицию с микронутриентами, регулирующими углеводный обмен. На основании имеющихся материалов и собственных исследований характеристик действующих начал сырьевых компонентов дано научное обоснование качественного и количественного состава рецептурной формулы БАД, обладающей синергическими свойствами в отношении коррекции метаболических нарушений при сахарном диабете $[9 ; 10 ; 11 ; 12 ; 13]$ (табл. 1).

Рецептурные компоненты - листья березы, черники и малины, корни девясила, артишока и имбиря положительно влияют на обменные процессы в организме, обеспечивая нормализацию количества сахара в крови. L-карнитин в сочетании с экстрактом лопуха, витаминами группы В, марганцем и хромом корректирует метаболизм жиров и углеводов. Эффект снижения вязкости крови, улучшения микроциркуляции, укрепления стенок сосудов обеспечивается функциональными свойствами экстракта гинкго билоба, витаминами РР, С, Е, кверцетином. Полынь проявляет противовоспалительное и противомикробное свойства, которые усиливаются бромелайном и папаином. Чеснок и зверобой активизируют защитную функцию при иммунодефицитных состояниях, обладают противомик-
Таблица 1. Рецептурный состав БАД Table 1. BAA Receipt Composition

\begin{tabular}{|c|c|}
\hline Компоненты & $\begin{array}{c}\text { Содержание, } \\
\text { мг }\end{array}$ \\
\hline 1. Черника (побеги) & 100 \\
\hline 2. Береза (лист) & 37,5 \\
\hline $\begin{array}{l}\text { 3. Премикс витаминный 1-03 (37,5 мг): } \\
\text { В1 - 0,19 мг; В2 - 0,19 мг; } \\
\text { В6 - 0,23 мг; В3 - 2,1 мг; } \\
\text { В5 - 0,89 мг; В12 - 0,4 мкг; } \\
\text { А - 0,2 мг; С- 10,3 мг; Е - 0,9 мг; } \\
\text { D3 - 1,35 мкг; фолиевая кислота - } \\
67,5 \text { мкг; биотин - 24,6 мкг }\end{array}$ & 37,5 \\
\hline 4. Брусника (лист) & 35 \\
\hline 5. Артишок (корень) & 25 \\
\hline 6. Зверобой (трава) & 25 \\
\hline 7. Крапива (лист) & 25 \\
\hline 8. Девясил (корень) & 25 \\
\hline 9. Горец птичий (трава) & 25 \\
\hline 10. Мята перечная (лист) & 12,5 \\
\hline 11. Лопух (экстракт корня) & 12,5 \\
\hline 12. Малина (экстракт листа) & 12,5 \\
\hline 13. Имбирь (корень) & 10 \\
\hline 14. Кверцетин & 7,5 \\
\hline 15. Рутин & 7,5 \\
\hline 16. Бромелайн & 5 \\
\hline 17. Гинкго билоба (экстракт) & 5 \\
\hline 18. Папаин & 5 \\
\hline 19. Чеснок сублимированный & 5 \\
\hline $\begin{array}{l}\text { 20. Цинка оксид } \\
\text { Содержание цинка }\end{array}$ & $\begin{array}{l}3,3 \\
2,3\end{array}$ \\
\hline 21. L-Карнитин & 2,5 \\
\hline 22. Кофермент Q 10 & 2,5 \\
\hline $\begin{array}{l}\text { 23. Марганца сульфат } \\
\text { Содержание марганца }\end{array}$ & $\begin{array}{l}2,5 \\
0,8\end{array}$ \\
\hline 24. Октакозанол & 1,25 \\
\hline 25. Хрома пиколинат & 0,83 \\
\hline
\end{tabular}

робным действием. Трава зверобоя улучшает процессы пищеварения, характеризуется успокаивающим и желчегонным влиянием, участвует в восстановлении нервных клеток. Листья брусники положительно влияют на обменные процессы в почках, реализуя мочегонные и антисептические свойства. Описанные выше действующие вещества фитокомплекса отличаются полезным сочетанием сахаропонижающего действия с одновременной поддержкой функциональной активности поджелудочной железы. 
В производстве БАД использована технология таблетирования с последующим дозированием биоактивного комплекса, с прессованием активных компонентов и вспомогательных веществ. Таблетированная форма имеет преимущества: незначительный объем, заданное количество активных ингредиентов, удобство хранения. Таблетированный биологически активный комплекс защищен специальным пленочным покрытием, которое позволяет повысить прочность таблетки, предотвратить воздействие агрессивных внешних факторов - света, влаги, кислорода, углекислоты.

Определены регламентируемые показатели качества и пищевой ценности (табл. 2), а также критерии безопасности разработанного специализированного продукта (табл. 3, 4).

Пищевая ценность определяет функциональные свойства продукта, способствующие оптимизации уровня глюкозы в крови человека, улучшение функции поджелудочной железы и, в целом, поддерживающие обмен веществ при сахарном диабете.

Спустя 36 месяцев хранения каких-либо изменений не выявлено. Полученные данные соответствуют требованиям, предъявляемым к данному виду продукции и свидетельствуют о ее санитарно-гигиеническом благополучии. По истечении 39 месяцев отмечены незначительные изменения вкуса и запаха, что позволило устано-

Таблица 2. Показатели качества и пищевой ценности разработанного специализированного продукта Table 2. Quality and Nutritional Value Indicators of the Specialized Product

\begin{tabular}{|c|c|}
\hline \multicolumn{2}{|r|}{ Качество } \\
\hline Показатель & Значение \\
\hline Внешний вид & Таблетки овальной формы, покрытые оболочкой или без нее \\
\hline Средняя масса таблетки, г & От 0,47 до 0,53 \\
\hline Цвет оболочки & Белый \\
\hline Распадаемость, мин, не более & 30 \\
\hline Цвет таблетки под оболочкой & Зеленый (оттенки с вкраплениями) \\
\hline Вкус и запах & Специфический \\
\hline Прочность на излом, Н, не менее & 90 \\
\hline Прочность на истирание, \% не менее & 97 \\
\hline \multicolumn{2}{|c|}{ Пищевая ценность } \\
\hline Показатель & Содержание в 1 таблетке, мг, не менее \\
\hline Витамин С & 8,6 \\
\hline Хром & 0,01 \\
\hline Цинк & 2,3 \\
\hline Флавоноиды & 10 \\
\hline Танины & 20 \\
\hline Марганец & 0,8 \\
\hline
\end{tabular}

Таблица 3. Санитарно-гигиенические показатели разработанного специализированного продукта Table 3. Sanitary and Hygienic Indicators of the Developed Specialized Product

\section{Показатель}

КМАФанМ, КОЕ/г, не более

В. cereus, KOE/г, не более

Дрожжи, KOE/г, не более

Плесени, КОЕ/г, не более

$$
\text { E CoLi, в } 1,0 \text { г }
$$

Масса продукта (г), S. aureus, в 1,0 г

в которой не допускаются

Патогенные,

Допустимый уровень [11]

$1 \cdot 10^{4}$
$2 \cdot 10^{2}$
100
100

Фактическое содержание

\section{0}

Менее 100

Менее 10

Менее 10 в том числе сальмонеллы, в 1,0 г

БГКП (колиформы), в 0,1 г 
Таблица 4. Санитарно-токсикологические показатели разработанного специализированного продукта, мг/кг (для радионуклидов, Бк/кг)

Table 4. Sanitary and Hygienic Indicators of the Specialized Product

\begin{tabular}{|c|c|c|c|}
\hline \multicolumn{2}{|c|}{ Показатель } & $\begin{array}{l}\text { Допустимый уровень, } \\
\text { не более }\end{array}$ & $\begin{array}{l}\text { Фактическое } \\
\text { содержание }\end{array}$ \\
\hline \multirow{4}{*}{$\begin{array}{l}\text { Токсичные } \\
\text { элементы }\end{array}$} & Мышьяк & 0,5 & Менее 0,05 \\
\hline & Кадмий & 1,0 & 0,066 \\
\hline & Ртуть & 0,1 & Менее 0,05 \\
\hline & Свинец & 6,0 & 1,26 \\
\hline \multirow{4}{*}{ Пестициды } & Гексахлорциклогексан (a, $\beta$, v-изомеры) & 0,1 & Менее 0,005 \\
\hline & Ддт и его метаболиты & 0,1 & Менее 0,005 \\
\hline & Гептахлор & 0,002 & Менее 0,002 \\
\hline & Алдрин & 0,002 & Менее 0,002 \\
\hline
\end{tabular}

вить регламентируемые сроки хранения - 3 года со дня изготовления.

Эффективность и функциональная направленность разработанного продукта подтверждены в ходе клинических испытаний. Изучена динамика содержания глюкозы в крови натощак и после приема пищи. У пациентов, принимавших БАД, наблюдалось достоверное снижение содержания глюкозы в венозной крови на 18,6 \% $(10,3 \pm 0,36-8,0 \pm 0,28)$, в капиллярной - на $21,3 \%$ $(8,4 \pm 0,5-6,3 \pm 0,4)$, что свидетельствует о более полноценном ее усвоении, а также снижении

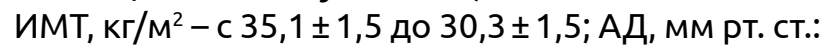
систолического и диастолического соответственно - $135 \pm 2,6-121 \pm 2,8$ и 83,7 $\pm 1,4-75 \pm 1,6$; базальной и пищевой гликемии через 40 мин после

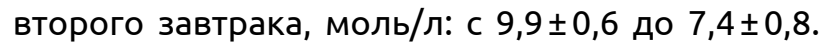
Установлены положительные изменения жирового обмена и снижение уровня общего холестерина на $28 \%$ от исходного; на 23 \% уменьшалось количество триглицеридов. Пациенты отмечали улучшение самочувствия, отсутствие жажды и сухости во рту.

Таким образом, получены доказательные клинические материалы о наличии профилактического эффекта специализированного продукта в отношении отрицательной динамики сахарного диабета. Показана способность фактора питания оптимизировать уровень глюкозы в крови, улучшать функции поджелудочной железы и пищеварительной системы в целом, активизировать процессы микроциркуляции и нормализации углеводно-жирового обмена. Прием фитокомплекса рекомендован лицам с нарушением толерантности к глюкозе и больным сахарным диабетом в количестве 2 таблеток 2 раза в день во время еды в течение одного месяца в комплексе с противодиабетическими препаратами с целью улучшения качества жизни и предупреждения развития осложнений заболевания.
Употребление четырех таблеток БАД согласно рекомендациям обеспечивает гарантированное поступление регламентируемых эссенциальных нутриентов, мг (\% от рекомендуемой нормы): витамин С - 34,4 $(38,2)$; хром - 0,04 $(80,0)$; цинк - 9,2 $(76,6) ;$ флавоноиды - $40(16,0)$; танины - $80(80,0)$; марганец - 3,2 $(160,0)$.

Специализированный продукт прошел промышленные испытания и включен в производственный цикл НПО «Арт Лайф» (г. Томск, Россия). Стабильность качественных характеристик и конкурентоспособность продукции обеспечиваются внедрением на предприятиях компании комплексной системы менеджмента, соответствующей требованиям ISO 9001, 22000 и правилам GMP.

\section{Выводы}

1. Обоснован количественный и качественный состав рецептуры специализированного продукта в форме БАД с учетом биохимической и фармакологической характеристик исходных ингредиентов. Определены регламентируемые показатели пищевой ценности. Одна таблетка БАД содержит, мг, не менее: аскорбиновая кислота - 8,6; хром - 0,1; цинк - 2,3; флавоноиды 10; тонины - 20; марганец-0,8.

2. Результаты санитарно-гигиенических и санитарно-токсикологических исследований свидетельствуют о соответствии продукта требованиям безопасности на протяжении 36 месяцев хранения, что позволило определить указанный срок как регламентируемый.

3. Эффективность и функциональная направленность разработанного специализированного продукта подтверждены клиническими испытаниями путем включения БАД в рацион больных сахарным диабетом II типа. Продукт рекомендован к приему в количестве 2 таблеток 2 раза в день во время приема пищи. 


\section{Библиографический список}

1. Герасименко Н.Ф., Позняковский В.М., Челнакова Н.Г. Методологические аспекты полноценного, безопасного питания: значение в сохранении здоровья и работоспособности // Человек. Спорт. Медицина. 2017. № 1, Т. 17. С. 79-86.

2. Герасименко Н.Ф., Позняковский В.М., Челнакова Н.Г. Здоровое питание и его роль в обеспечении качества жизни // Технологии пищевой и перерабатывающей промышленности АПК - продукты здорового питания. 2016. № 4 (12). С. 52-57.

3. Позняковский В.М., Чугунова О.В., Тамова М.Ю. Пищевые ингредиенты и биологически активные добавки: учебник. М.: ИНФРА-М, 2017. 143 C.

4. Позняковский В. М. Эволюция питания и формирования нутриома современного человека // Индустрия питания. 2017. № 3. C. 5-12.

5. Кунцевич А.К., Мустафина С.В., Малютина С.К., Веревкин Е.Г., Рымар 0.Д. Популяционное исследование питания городского населения при сахарном диабете 2 типа // Сахарный диабет. 2015. № 4. C. 59-65.

6. Шмюэль Л., Филиппов Ю.И., Горелышев А.С. Сахарный диабет 2 типа: время изменить концепцию // Сахарный диабет. 2013. № 1 (58). C. 91-102.

7. Aas, A.M.; Johansson, L.; Bjerkan, K. Do Norwegians with Diabetes Have a Healthier Diet Than the General Population? Norsk. Epidemiologi.2013; 23(1). Pp. 61-74.

8. Mann, J.I.; De Leeuw, I.; Hermansen, K. Evidence-Based Nutritional Approaches to the Treatment and Prevention of Diabetes Mellitus. Nutr. Metab. Cardiovasc. Dis. 2004. 14(6). Pp. 373-394.

9. Георгиевский В.П., Комиссаренко Н.Ф., Дмитрук С.Е. Биологически активные вещества лекарственных растений. Новосибирск: Наука, 1990. 333 с.

10. Гичев Ю.Ю., Гичев Ю.П. Новое руководство по микронутриенто логии (биологически активные добавки к пище и здоровье). М.: Триада - Х, 2012.317 c.

11. Лебедев В.П. Клиническая фитотерапия. Новосибирск: Наука, 2003. $368 \mathrm{C}$.

12. Майтаков А.Л., Литвина Е.А., Позняковский В.М. Научное обо снование рецептурной формулы и регламентируемые показатели качества быстрорастворимого напитка на основе местного сырья // АПК России. 2018. № 1, Т. 25. С. 121-126.

13. Титоренко Е.Ю., Яковлева Л.А., Позняковский В.М. и др. 06осно вание рецептуры функционального напитка на основе местного растительного сырья // Технология пищевой и перерабатывающей промышленности АПК - продукты здорового питания. 2017. №1 (15). С. 41-48.

\section{Bibliography}

1. Gerasimenko, N.F.; Poznyakovskiy, V.M.; Chelnakova, N.G. Metodologicheskie Aspekty Polnocennogo, Bezopasnogo Pitaniya: Znachenie v Sohranenii Zdorovya I Rabotosposobnosti [Methodological Aspects of a Complete Safe Nutrition: Importance in Health And Efficiency Maintaining]. Chelovek. Sport. Medicina. 2017. № 1, T. 17. Pp. 79-86.

2. Gerasimenko, N.F.; Poznyakovskiy, V.M.; Chelnakova, N.G. Zdorovoe Pitanie i Ego Rol v Obespechenii Kachestva Zhizni [Healthy Eating and Its Role in Life Quality Ensuring]. Tekhnologii Pishchevoj i Pererabatyvayushchej Promyshlennosti APK - Produkty Zdorovogo Pitaniya. 2016. № 4 (12). Pp. 52-57.

3. Poznyakovskiy, V.M.; Chugunova, O.V.; Tamova, M.Yu. Pishchevye Ingredienty i Biologicheski Aktivnye Dobavki [Food Ingredients and Biologically Active Aditives]: Uchebnik. M.: INFRA-M, 2017. 143 p.

4. Poznyakovskiy, V. M. Evolyuciya Pitaniya i Formirovaniya Nutrioma Sovremennogo Cheloveka [Nutrition Evolution and Nutriom Formation of the Modern Human]. Industriya Pitaniya. 2017. № 3. Pp. 5-12.

5. Kuncevich, A.K.; Mustafina, S.V.; Malyutina, S.K.; Verevkin, E.G.; Rymar, O.D. Populyacionnoe Issledovanie Pitaniya Corodskogo Naseleniya pri Saharnom Diabete 2 Tipa [Population Study Of Urban Nutrition in the Diabetes Type 2]. Saharnyj Diabet. 2015. № 4. Pp. 59-65.

6. Shmyuel, L.; Filippov, Yu.I.; Gorelyshev, A.S. Saharnyj Diabet 2 Tipa: Vremya Izmenit Koncepciyu [Diabetes Type 2: Time to Change the Concept]. Saharnyj Diabet. 2013. № 1 (58). Pp. 91-102.

7. Aas, A.M.; Johansson, L.; Bjerkan, K. Do Norwegians with Diabetes Have a Healthier Diet Than the General Population? Norsk. Epidemiologi.2013; 23(1). Pp. 61-74.

8. Mann, J.I.; De Leeuw, I.; Hermansen, K. Evidence-Based Nutritional Approaches to the Treatment and Prevention of Diabetes Mellitus. Nutr. Metab. Cardiovasc. Dis. 2004. 14(6). Pp. 373-394.

9. Georgievskij, V.P.; Komissarenko, N.F.; Dmitruk, S.E. Biologicheski Aktivnye Veshchestva Lekarstvennyh Rastenij [Biologically Active Substances of Medicinal Plants]. Novosibirsk: Nauka, 1990. 333 p.

10. Gichev, Yu.Yu.; Gichev, Yu.P. Novoe Rukovodstvo po Mikronutrientologii (Biologicheski Aktivnye Dobavki k Pishche i Zdorovje) [New Guide to the Micronutrientology (Biologically Active Additives and the Health)]. M.: Triada - X, 2012.317 p.

11. Lebedev, V.P. Klinicheskaya Fitoterapiya [Clinical Herbal Medicine]. Novosibirsk: Nauka, 2003. 368 p.

12. Majtakov, A.L.; Litvina, E.A.; Poznyakovskiy, V.M. Nauchnoe Obosnovanie Recepturnoj Formuly i Reglamentiruemye Pokazateli Kachestva Bystrorastvorimogo Napitka na Osnove Mestnogo Syrya [Scientific Substantiation of a Receipt and Regulated Quality Indicators of Instant Drink on the Local Raw Materials Basis]. APK Rossii. 2018. № 1, T. 25. Pp. 121-126.

13. Titorenko, E.Yu.; Yakovleva, L.A.; Poznyakovskiy, V.M. Obosnovanie Receptury Funkcionalnogo Napitka na Osnove Mestnogo Rastitelnogo Syrya [Substantiation of the Functional Drink Receipt Based on the Local Vegetable Raw Materials]. Tekhnologiya Pishchevoj i Pererabatyvayushchej Promyshlennosti APK - Produkty Zdorovogo Pitaniya. 2017. №1 (15). Pp. 41-48. 


\section{Информация 06 авторах / Information about Authors}

\section{Калимуллин \\ Марат Ильдусович}

Kalimullin, Marat Ildusovich

тел./Phone: +7 905-912-44-44 E-mail:sd@leszdrav.ru

\section{Сади \\ Сай-Суу Сайын-ооловна}

Sadi,

Sai-Suu Sayin-oolovna

тел./Phone: +7 996-331-55-24

E-mail: saysuu.sadi@mail.ru

\section{Австриевских Александр Николаевич}

Avstriyevskikh, Aleksandr Nikolayevich

тел./Phone: +7 (3832) 55-60-92 E-mail: Alexcander@artlife.ru

\section{Позняковский Валерий Михайлович \\ Poznyakovskiy, Valeriy Mikhaylovich}

Тел./Phone: +7 (343) 221-26-72 E-mail:pvm1947@bk.ru
Кандидат экономических наук, докторант базовой кафедры пищевой индустрии и функционального питания

Кузбасская государственная сельскохозяйственная академия

650021, Российская Федерация, г. Кемерово, ул. Карла Маркса, 12

Candidate of Economic Science, Postgraduate Student of the Basic Food Industry and Functional Nutrition Department

Kuzbass State Agricultural Academy

650021, Russian Federation, Kemerovo, Karla Marx St., 12

Магистрант базовой кафедры пищевой индустрии и функционального питания Кузбасская государственная сельскохозяйственная академия 650021, Российская Федерация, г. Кемерово, ул. Карла Маркса, 12

Master Student of the Basic Food Industry and Functional Nutrition Department Kuzbass State Agricultural Academy 650021, Russian Federation, Kemerovo, Karla Marx St., 12

\author{
Доктор технических наук, профессор \\ Директор НПО «Арт Лайф» \\ 634034, Российская Федерация, г. Томск, ул. Нахимова, 8/2 \\ Doctor of Technical Science, Professor \\ General Director of the Scientific and Production Association "Art Life" \\ 634034, Russian Federation, Tomsk, Nakhimova St., 8/2
}

Заслуженный деятель науки РФ, доктор биологических наук, профессор, профессор кафедры технологии питания Уральский государственный экономический университет 620144, Российская Федерация, г. Екатеринбург, 8 Марта / Народной Воли, 62/45

Honored Scientist of the Russian Federation, Doctor of Biological Science, Professor, Professor of the Food Technology Department Ural State University of Economics 620144, Russian Federation, Ekaterinburg, 8 March St. / Narodnoy Voli St., 62/45 ORCID: https://orcid.org/0000-0001-7193-778X 